\title{
Enalapril attenuates endoplasmic reticulum stress and mitochondrial injury induced by myocardial infarction via activation of the TAK1/NFAT pathway in mice
}

\author{
XING RONG ${ }^{1,2 *}$, DONGHUI GE ${ }^{1 *}$, LILI YU ${ }^{2}$, LEI LI $^{2}$, MAOPING CHU ${ }^{2}$ and HAITAO LV ${ }^{1}$ \\ ${ }^{1}$ Department of Cardiology, Children's Hospital of Soochow University, Suzhou, Jiangsu 215025; ${ }^{2}$ Children's Heart Center, \\ The Second Affiliated Hospital and Yuying Children's Hospital of Wenzhou Medical University, Institute of Cardiovascular \\ Development and Translational Medicine, Wenzhou Medical University, Wenzhou, Zhejiang 325027, P.R. China
}

Received November 10, 2018; Accepted August 12, 2019

DOI: $10.3892 /$ etm.2019.8280

\begin{abstract}
The present study investigated the effect of enalapril on myocardial infarction (MI) and its mechanism of action in mice. Treatment with enalapril significantly attenuated cellular apoptosis and death. In vivo, enalapril treatment alleviated MI injury, and decreased myocardial apoptosis and the size of the infarct area. This was paralleled by increased Bcl-2 expression, decreased Bax expression, a decreased caspase-3 level, decreased expression of endoplasmic reticulum stress-associated proteins, including activating transcription factor 6 and $78 \mathrm{kDa}$ glucose-regulated protein, and fewer TUNEL-positive cells in the heart. Furthermore, enalapril-treatment increased transforming growth factor-activated kinase 1/nuclear factor of activated T cells 3 signaling, which protected the myocardium.
\end{abstract}

Correspondence to: Dr Haitao Lv, Department of Cardiology, Children's Hospital of Soochow University, 92 Zhong Nan Street, Suzhou, Jiangsu 215025, P.R. China

E-mail: haitaosz@163.com

Dr Maoping Chu, Children's Heart Center, The Second Affiliated Hospital and Yuying Children's Hospital of Wenzhou Medical University, Institute of Cardiovascular Development and Translational Medicine, Wenzhou Medical University, 109 Xueyuan Xi Road, Wenzhou, Zhejiang 325027, P.R. China

E-mail: chmping@hotmail.com

*Contributed equally

Abbreviations: Ang II, angiotensin II; ERS, endoplasmic reticulum stress; MI, myocardial infarction; NFAT3, nuclear factor of activated T cells 3; TAK1, transforming growth factor- $\beta$-activated kinase 1 ; RAS, rennin-angiotensin system

Key words: enalapril, myocardial infarction, cardiac remodeling, transforming growth factor- $\beta$-activated kinase $1 /$ nuclear factor of activated $T$ cells pathway, apoptosis

\section{Introduction}

Although there are numerous treatment methods for ischemic coronary heart disease, this condition remains the leading cause of mortality worldwide and is often associated with sudden death (1). Apoptosis, a well-defined process, serves an important role in myocardial infarction (MI), via both the extrinsic and intrinsic pathways $(2,3)$. Several studies have indicated that the renin-angiotensin system (RAS) is activated following MI and the release of angiotensin II (Ang II) leads to myocardial damage (4).

Enalapril, an angiotensin-converting enzyme inhibitor, significantly decreases MI-associated mortality (5-7). Over the previous 2 decades, there has been a marked increase in the use of enalapril-treatment, which has contributed to the decreased rates of mortality observed (8). Furthermore, treatment with enalapril significantly prevents apoptosis, endoplasmic reticulum (ER) stress and mitochondrial injury (9). However, to the best of our knowledge, the underlying mechanism of the effect of enalapril on MI remains uncertain.

Transforming growth factor-activated kinase 1 (TAK1) serves an important role as a survival signal. The deletion of TAK1 induces apoptosis in hematopoietic cells and hepatocytes, resulting in bone marrow and liver failure in mice, and the downregulated expression of pro-survival genes (10). In an additional study, TAK1 was demonstrated to drive cell survival as a responsive kinase (11). Furthermore, TAK1 has been suggested to inhibit apoptosis in numerous cell lines. For example, TAK1-silencing induced apoptosis of lymphoma cells (12). Another study confirmed increased apoptosis levels in TAK1-deficient B cells (13). Furthermore, TAK1 serves as a survival signal and protects hematopoietic stem and progenitor cells from apoptosis (14). Nuclear factor of activated T cells 3 (NFAT3) is regulated by calcium signaling. De Windt et al (15) suggested that NFAT3 is associated with the likely mechanism of calcineurin-induced protection against apoptosis in myocytes. In addition, inhibition of NFAT3 has been confirmed to induce apoptosis in cortical neurons (16). However, to the best of our knowledge, the role of the TAK1/NFAT3 pathway in MI treated with enalapril remains unknown. Therefore, the present study aimed to determine the mechanism of enalapril-treatment for MI in mice. 


\section{Materials and methods}

MI mouse model and enalapril treatment. All animal experiments were approved by the Animal Ethics Committee of Wenzhou Medical University (no., wydw2017-0007) and were in accordance with the National Institute of Health Guidelines for the Care and Use of Laboratory Animals (17). Adult male C57BL/6 mice (20-25 g) aged 6-8 weeks (Shanghai Laboratory Animal Center) were housed (temperature, $24 \pm 1^{\circ} \mathrm{C}$; humidity, $45 \pm 10 \%$ ) in a specific pathogen-free environment, with access to standard food and sterile tap water ad libitum under $12 \mathrm{~h}$ light/dark cycles and allowed to acclimatize for $\geq 72 \mathrm{~h}$ prior to surgery. The animal use and care protocol conformed to the Guide for the Care and Use of Laboratory Animals (17). All surgical procedures were performed under anesthesia using intraperitoneal (i.p.) injection of ketamine $(90 \mathrm{mg} / \mathrm{kg}$ body weight) and xylazine (5 mg/kg body weight) (18). Anesthesia was assessed by measuring the toe pinch reflex. Adequate anesthesia resulted in a complete lack of response in the extremity. A left thoracotomy was performed via the fourth intercostal space, the heart was exposed and the pericardium was opened. The left anterior descending coronary artery (LAD) was ligated with a 7-0 silk suture near its origin between the pulmonary outflow tract and the edge of the left atrium. Acute myocardial ischemia was deemed successful when the anterior wall of the left ventricle (LV) became pale and when echocardiography demonstrated a decreased ejection fraction 1 week following surgery. Sham-operated mice were subjected to the same procedure, but the suture around the LAD was not tied. Animals were kept on a heating pad until they awoke. Mice that survived surgery were randomly assigned to different treatment groups ( $\mathrm{n}=6-10$ per group). Animals that underwent the same surgical procedure without coronary artery ligation served as a control group ( $\mathrm{n}=6-10$ per group). MI mice were treated with a dose of $20 \mathrm{mg} / \mathrm{kg}(19,20)$ enalapril (Sigma-Aldrich; Merck KGaA) or an equal amount of drinking water daily through gastric gavage, following echocardiography, for 3 weeks. These groups were termed MI + Ena and MI groups, respectively.

Echocardiography. At the end of treatment, cardiac systolic function was measured under anesthesia with thiopentone (method, intraperitoneal injection; dose, $20 \mathrm{mg} / \mathrm{kg}$ body weight) (21). Mice were kept on a heating pad in the left lateral decubitus or supine position and two-dimensional images were recorded. LV parameters, including the internal diastolic diameter (LVIDd) and internal systolic diameter (LVIDs), were obtained from M-mode interrogation in the long-axis view. The LV percentage fractional shortening (LV\%FS) and LV ejection fraction (LVEF) were calculated as follows: $\mathrm{LV} \% \mathrm{FS}=(\mathrm{LVIDd}-\mathrm{LVIDs}) / \mathrm{LVIDd} \times 100$; and LVEF $=\left[(\text { LVIDd })^{3}-(\text { LVIDs })^{3}\right] /(\text { LVIDd })^{3} \times 100$. All echocardiographic measurements were averaged from at least 3 independent cardiac cycles.

Terminal deoxynucleotidyl transferase dUTP nick-end labeling (TUNEL) assay. At the end of the treatment period, all mice were euthanized with an overdose of sodium pentobarbital $(200 \mathrm{mg} / \mathrm{kg}$, i.p.). Animal death was verified by observation of cardiac arrest and pupil enlargement for
$1 \mathrm{~min}$. The humane endpoints established in this study were as follows: Impaired ambulation that prevented animals from reaching food or water; excessive weight loss and extreme emaciation; lack of physical or mental alertness; difficult labored breathing; and prolonged inability to remain upright. Animals were observed a minimum of twice daily, with more frequent observations immediately after dosing and when increased morbidity or mortality was expected (17). The heart was then removed and fixed in $10 \%$ formalin for $24-48 \mathrm{~h}$ at $4^{\circ} \mathrm{C}$. Formalin-fixed heart tissues were then embedded in paraffin and sections were cut ( 4 $\mu \mathrm{m}$ thick). Cardiomyocyte apoptosis was detected using a one-step TUNEL Apoptosis assay kit at $37^{\circ} \mathrm{C}$ for $1 \mathrm{~h}$ (Roche Diagnostics $\mathrm{GmbH}$ ), according to the manufacturer's protocol, followed by DAPI staining $(10 \mu \mathrm{g} / \mathrm{ml}$; Beijing Solarbio Science \& Technology Co., Ltd.) at room temperature for $2 \mathrm{~min}$. Anti-fade mounting medium was then added (cat. no. P0126; Beyotime Institute of Biotechnology) to each slide. Images were obtained from five fields per slide using confocal microscopy (magnification x400; NIKON A1R/A1; Nikon Corporation).

Masson's trichrome (MT) staining and immunohistochemistry. Heart tissues were processed as described above. Fibrosis was assessed by MT staining (Beijing Suolai Bao Technology Co., Ltd.), according to the manufacturer's protocol in addition to the protocol described previously (22). Briefly, the tissue sections were stained with ponceau for $7 \mathrm{~min}$, aniline blue for $7 \mathrm{~min}$ and phosphomolybdic acid for $2 \mathrm{~min}$ at room temperature.

Immunohistochemistry (confocal, magnification $\mathrm{x} 400$ ) was performed to detect associated proteins, including c-caspase 3 and NFAT3. Briefly, the slides were heated at $60^{\circ} \mathrm{C}$ for $1 \mathrm{~h}$, deparaffinized and hydrated with xylene, graded ethyl alcohols and $\mathrm{dH}_{2} \mathrm{O}$. Following antigen retrieval [7 min of boiling and $3 \mathrm{~min}$ in sodium citrate buffer $(10 \mathrm{mM}$, $\mathrm{pH}$ 6.0) using an induction cooker], the sections were treated for 15 min with $3 \% \mathrm{H}_{2} \mathrm{O}_{2}$ and blocked for 30 min with $10 \%$ goat serum (Abcam) at room temperature. The sections were then incubated overnight at $4^{\circ} \mathrm{C}$ with anti-cleaved caspase-3 (cat. no. 9694; Cell Signaling Technology, Inc.; 1:1,000) and anti-NFAT3 (cat. no. ab3347; Abcam; 1:1,000) primary antibodies, followed by incubation with horseradish peroxidase-conjugated secondary antibody (1:3,000; cat. no. 7074; Cell Signaling Technology, Inc.) at $37^{\circ} \mathrm{C}$ for $30 \mathrm{~min}$. Immunostaining was visualized using $\mathrm{DAB}$ chromogen by incubation for $1 \mathrm{~min}$ at room temperature (cat. no. D4293; Sigma-Aldrich; Merck KGaA) and sections were counterstained with Mayer's hematoxylin for between $30 \mathrm{sec}$ and $1 \mathrm{~min}$ at room temperature.

Western blot analysis. Total proteins and nucleoproteins were extracted using Total Protein Extraction kit (Beyotime Institute of Biotechnology) and Nuclear and Cytoplasmic Protein Extraction Kit (Beyotime Institute of Biotechnology) for homogenized myocardial tissue samples. Protein concentrations were measured using a bicinchoninic acid assay. The equivalent of $60 \mu \mathrm{g}$ protein was separated on a $12 \%$ SDS-PAGE and transferred to $0.22 \mu \mathrm{m}$ polyvinylidene fluoride membranes. Next, the membranes were blocked with $5 \%$ fat-free milk for $2 \mathrm{~h}$ at $4^{\circ} \mathrm{C}$ and incubated with the relevant 
A

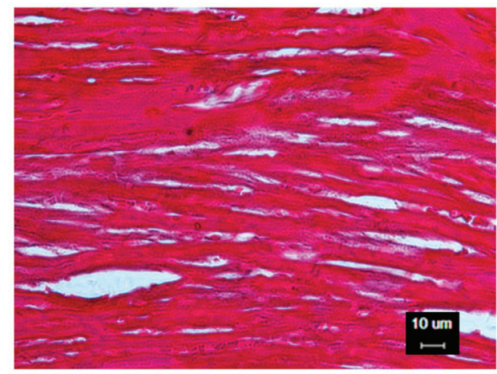

Sham

B

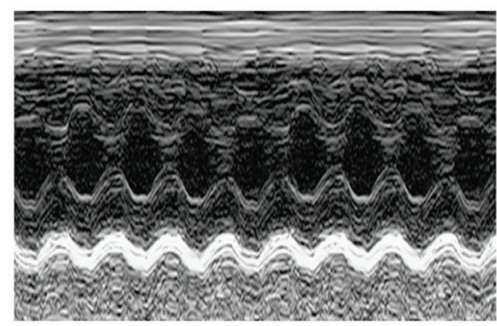

Sham

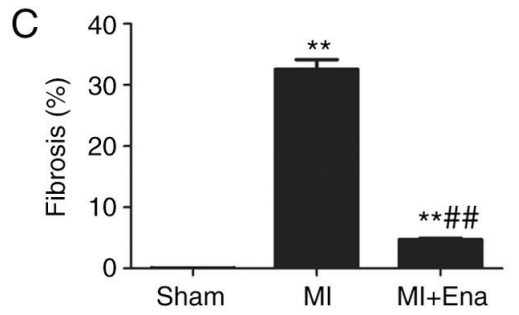

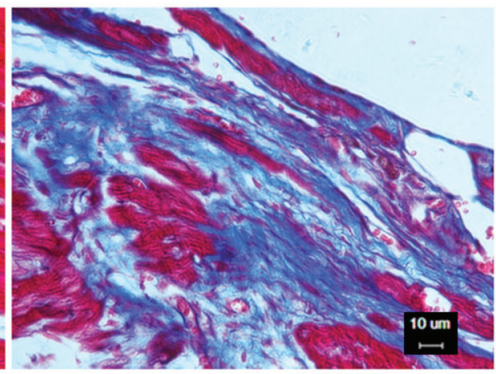

MI

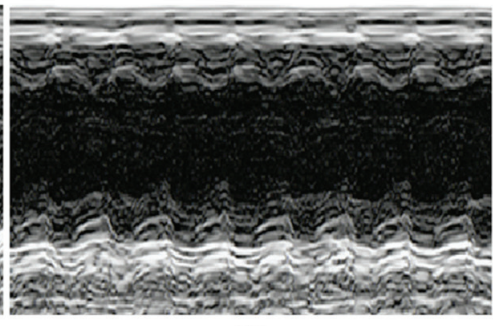

MI

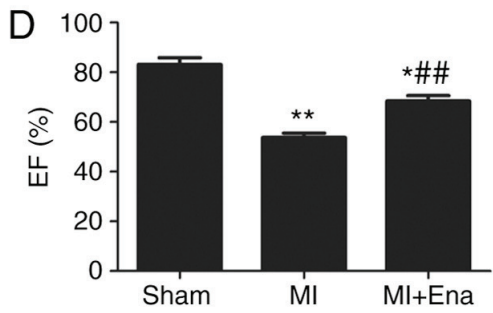

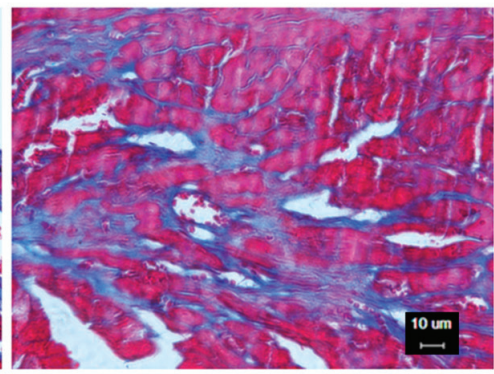

$\mathrm{Ml}+$ Ena

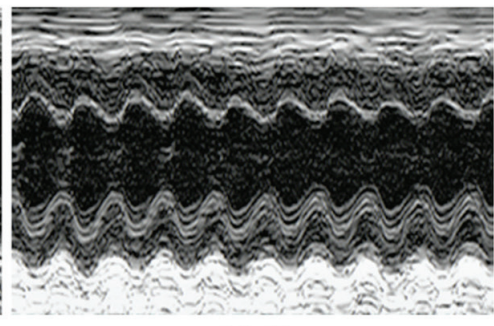

$\mathrm{Ml}+$ Ena

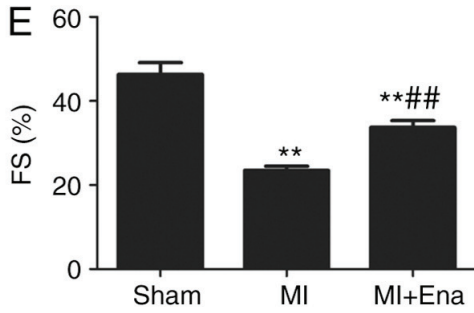

Figure 1. Enalapril decreases myocardial fibrosis and increases cardiac systolic function in the hearts of mice following MI. (A) Representative Masson's trichrome images of sections from the ischemic area of MI mice treated with enalapril or control. Scale bar, $10 \mu \mathrm{m}$. Magnification x400. (B) Representative images produced by echocardiography from different groups of mice (sham, MI and MI treated with enalapril). (C) Fibrosis in sham, MI and MI+Ena groups. (D) The EF and (E) FS at the end of treatment with enalapril or control. ${ }^{*} \mathrm{P}<0.05$ and ${ }^{* *} \mathrm{P}<0.01$ vs. sham group. ${ }^{\# \#} \mathrm{P}<0.01$ vs. MI group. MI, myocardial infarction; EF, ejection fraction; FS, fraction shortening; Ena, enalapril.

protein antibodies overnight at $4^{\circ} \mathrm{C}$, including antibodies against poly (ADP-ribose) polymerase (PARP)-1 (1:1,000; cat. no. 9532, Cell Signaling Technology, Inc.), caspase-9 (1:1,000; cat. no. 9508; Cell Signaling Technology, Inc.), cleaved caspase-9 (1:1,000; cat. no. 7237; Cell Signaling Technology, Inc.), caspase-3 (1:1,000; cat. no. 9665; Cell Signaling Technology, Inc.), cleaved caspase-3 (1:1,000; cat. no. 9694; Cell Signaling Technology, Inc.), 78 kDa glucose-regulated protein (GRP78; 1:500; cat. no. sc-13968; Santa Cruz Biotechnology, Inc.), activating transcription factor 6 (ATF6; 1:1,000; cat. no. 65880; Cell Signaling Technology, Inc.), Bcl-2 (1:1,000; cat. no. 3498; Cell Signaling Technology, Inc.), Bax (1:1,000; cat. no. 14796; Cell Signaling Technology, Inc.), TAK1 (1:1,000; cat. no. ab109526, Abcam), phosphorylated TAK1 (1:1,000; cat. no. 9339; Cell Signaling Technology, Inc.), NFAT3 (1:1,000; cat. no. ab3347; Abcam), $\beta$-actin (1:1,000; cat. no. 3700; Cell Signaling Technology, Inc.) and Lamin B1 (1:1,000; cat. no. 13435; Cell Signaling Technology, Inc.). The membranes were washed with TBS containing $1 \%$ Tween-20 and incubated with horseradish peroxidase-conjugated second antibody (1:3,000; cat. no. 7074; Cell Signaling Technology, Inc.) for $2 \mathrm{~h}$ at room temperature. ECL was used as chromogenic method. Signals were visualized using a ChemiDicTMXRS + Imaging System (Bio-Rad Laboratories,
Inc.) and the band density was quantified using the Image $\mathrm{Lab}^{\text {TM }} 5.2$ software (Bio-Rad Laboratories, Inc.). The amount of protein was analyzed using Image-Pro Plus (version 6.0; Media Cybernetics, Inc.) and normalized to the respective controls.

Statistical analysis. All data are presented as the mean \pm standard deviation from at least 3 independent experiments. All statistical analyses were performed using the SPSS 19.0 statistical software package (IBM Corp.). One-way ANOVA was used to compare data from multiple groups. For data with homogeneity of variance, the Least Significant Difference post-hoc test was used, and the Dunnett's T3 post-hoc test was performed for those data with irregular variance. $\mathrm{P}<0.05$ was considered to indicate a statistically significant difference.

\section{Results}

Effect of enalapril on the MI-evoked fibrotic response and cardiac systolic function in vivo. To evaluate the protective effect of enalapril on MI, the effects of enalapril-treatment on myocardial fibrosis in mice were investigated and the results are presented in Fig. 1A. Myocardial fibrosis was not 
Table I. Comparison of myocardial fibrosis, EF and FS data between groups.

\begin{tabular}{lccc}
\hline Groups & Myocardial fibrosis (\%) & Ejection fraction (EF) (\%) & Fraction shortening (FS) (\%) \\
\hline Sham & $0.06 \pm 0.05$ & $83.17 \pm 5.40$ & $46.32 \pm 5.64$ \\
MI & $32.6 \pm 3.44^{\mathrm{b}}$ & $53.76 \pm 4.07^{\mathrm{b}}$ & $23.48 \pm 2.25^{\mathrm{b}}$ \\
MI+Ena & $4.72 \pm 0.50^{\mathrm{b}, \mathrm{c}}$ & $68.43 \pm 5.36^{\mathrm{a}, \mathrm{c}}$ & $33.73 \pm 3.86^{\mathrm{b}, \mathrm{c}}$ \\
F-value & 385.45 & 38.96 & 36.54 \\
P-value & $<0.01$ & $<0.01$ & $<0.01$ \\
\hline
\end{tabular}

EF, Ejection fraction; FS, fraction shortening; Ena, enalapril; MI, myocardial infarction. ${ }^{\mathrm{a}} \mathrm{P}<0.05$ and ${ }^{\mathrm{b}} \mathrm{P}<0.01 \mathrm{vs}$. Sham group. ${ }^{\mathrm{c}} \mathrm{P}<0.01 \mathrm{vs}$. MI group.

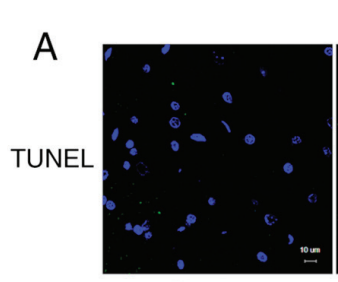

Sham

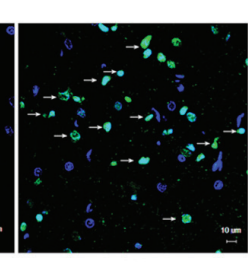

$\mathrm{Ml}$

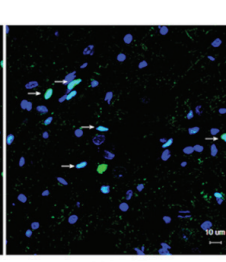

Ml+Ena
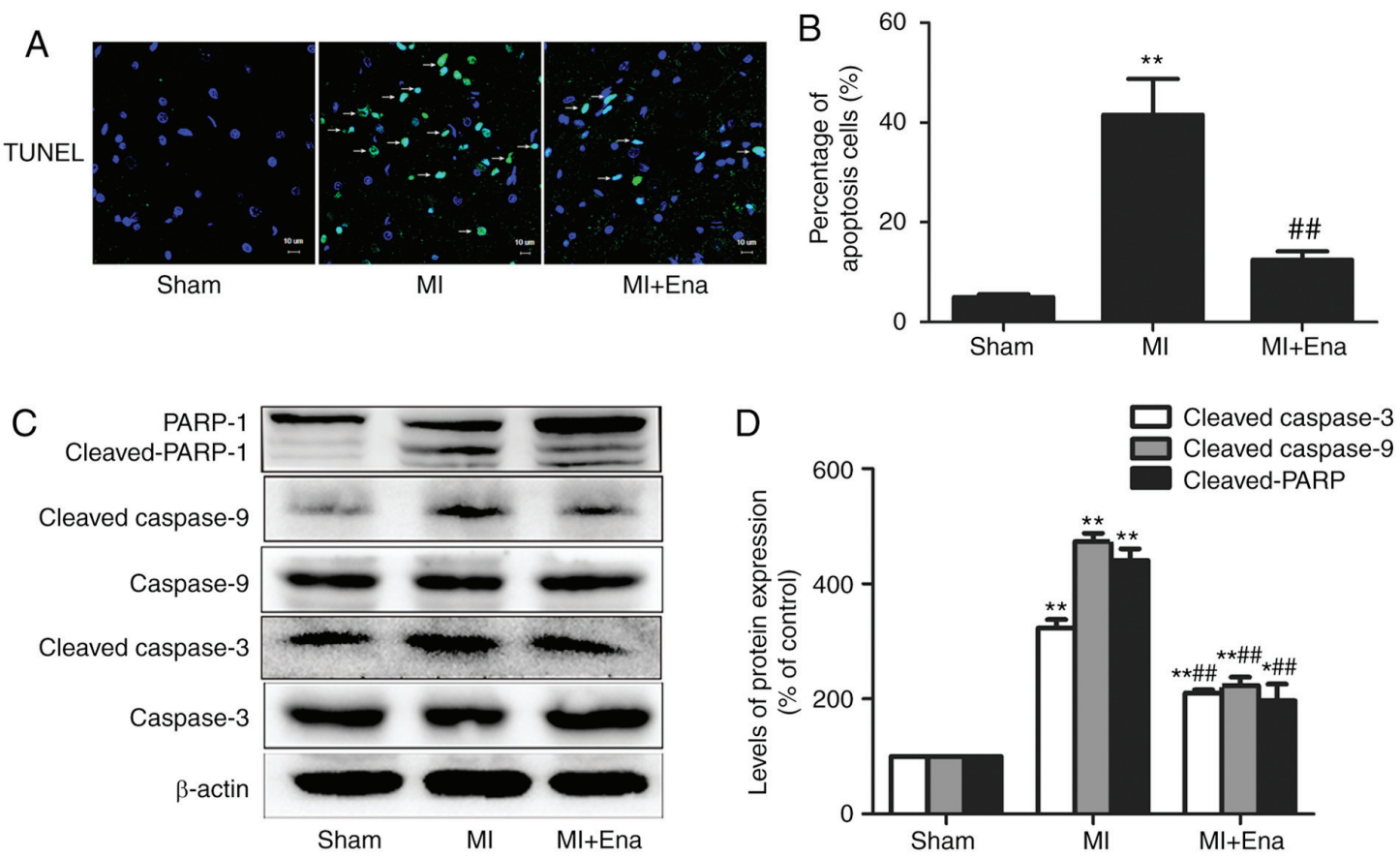

$\mathrm{E}$

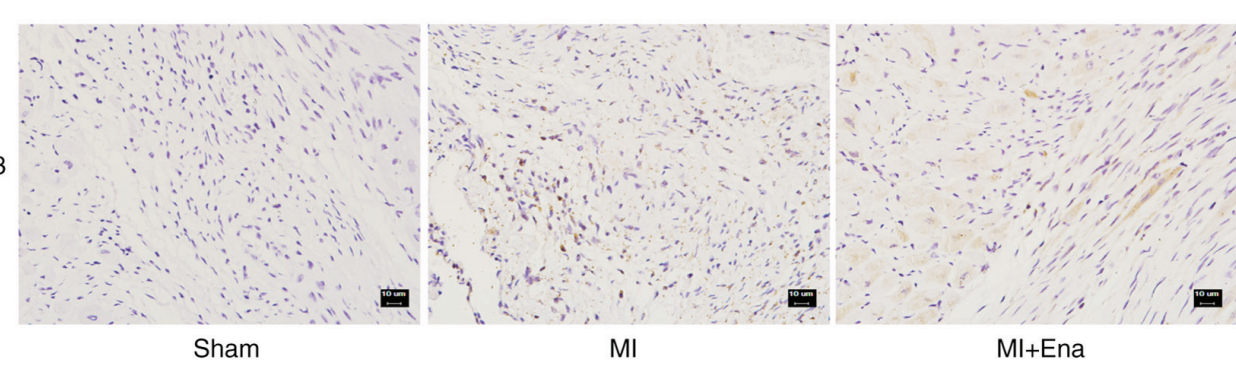

Figure 2. Enalapril decreases myocardial apoptosis in MI mice. (A) Representative TUNEL immunofluorescence images in different groups of mice. The white arrows indicate the TUNEL-positive cells. Scale bar, $10 \mu \mathrm{m}$. Magnification, x400. (B) Percentages of apoptosis-positive cells. (C) Endoplasmic reticulum stress-associated and mitochondrial dysfunction-associated proteins were detected by western blot analysis. Protein levels of cleaved PARP, cleaved caspase-3 and cleaved caspase-9 in the hearts of control mice, MI mice and MI mice treated with enalapril. (D) Optical density analysis of cleaved PARP, cleaved caspase-3 and cleaved caspase-9 in the heart tissues. (E) Immunohistochemical staining for cleaved caspase-3 in the hearts of control mice, MI mice and MI mice treated with enalapril. The data are presented as the mean \pm standard deviation $(\mathrm{n}=6)$. ${ }^{*} \mathrm{P}<0.05$ and ${ }^{* * *} \mathrm{P}<0.01$ vs. sham group. ${ }^{\# \#} \mathrm{P}<0.01$ vs. MI group. MI, myocardial infarction; PARP, poly (ADP-ribose) polymerase; Ena, enalapril.

observed in the control group. Compared with the MI group, the MI+Ena group presented with less myocardial fibrosis (Fig. 1A and C). Cardiac systolic function was also observed and measured by echocardiography, ejection fraction (EF) measurement and fraction shortening (FS) measurement
(Fig. 1B, D and E). Cardiac systolic function was normal in the control group (EF, 83.18\%; FS, 46.33\%). Compared with the MI group (EF, $53.76 \%$; FS, $23.48 \%$ ), the MI+Ena group (EF, 68.43\%; FS, 33.73\%) demonstrated a significant improvement in cardiac systolic function, suggesting that 
Table II. Comparison of myocardial apoptosis, cleaved caspase-3, cleaved caspase-9 and cleaved PARP between different groups .

\begin{tabular}{lccccr}
\hline & \multicolumn{4}{c}{ Groups } & \\
\cline { 2 - 4 } Data & Sham & MI & Mi-Ena & F-statistic & P-value \\
\hline Myocardial fibrosis (\%) & $5.0 \pm 1.0$ & $41.56 \pm 12.42^{\mathrm{b}}$ & $12.54 \pm 2.85^{\mathrm{c}}$ & 20.53 & $<0.01$ \\
Cleaved caspase-3 & $100 \pm 0.1$ & $323.33 \pm 25.17^{\mathrm{b}}$ & $210 \pm 10.0^{\mathrm{b}, \mathrm{c}}$ & 152.9 & $<0.01$ \\
Cleaved caspase-9 & $100 \pm 0.1$ & $473.33 \pm 25.17^{\mathrm{b}}$ & $223.33 \pm 25.17^{\mathrm{b}, \mathrm{c}}$ & 256.96 & $<0.01$ \\
Cleaved PARP & $100 \pm 0.1$ & $440.33 \pm 36.1^{\mathrm{b}}$ & $196.67 \pm 50.33^{\mathrm{a}, \mathrm{c}}$ & 72.03 & $<0.01$ \\
\hline
\end{tabular}

PARP, poly (ADP-ribose) polymerase; Ena, enalapril; MI, myocardial infarction. ${ }^{a} \mathrm{P}<0.05$ and ${ }^{b} \mathrm{P}<0.01$ vs. Sham group. ${ }^{\mathrm{c}} \mathrm{P}<0.01$ vs. MI group.

Table III. Comparison of GRP78, ATF6, Bax/Bcl-2, p-TAK1/TAK1 and NFAT3 expression between different groups.

\begin{tabular}{lccrrr}
\hline & \multicolumn{4}{c}{ Groups } & \\
\cline { 2 - 4 } Data & Sham & \multicolumn{1}{c}{ MI } & Mi-Ena & F-statistic & P-value \\
\hline GRP78 & $100 \pm 0.15$ & $331.67 \pm 27.54^{\mathrm{a}}$ & $168.33 \pm 16.1^{\mathrm{a}, \mathrm{d}}$ & 125.31 & $<0.01$ \\
ATF6 & $100 \pm 0.1$ & $235.0 \pm 15.0^{\mathrm{a}}$ & $140.0 \pm 10.0^{\mathrm{a}, \mathrm{d}}$ & 132.99 & $<0.01$ \\
Bax/Bcl-2 & $1.00 \pm 0.001$ & $2.99 \pm 0.44^{\mathrm{a}}$ & $0.64 \pm 0.03^{\mathrm{b}, \mathrm{c}}$ & 74.34 & $<0.01$ \\
p-TAK1/TAK1 & $1.00 \pm 0.003$ & $1.45 \pm 0.21^{\mathrm{a}}$ & $1.99 \pm 0.25^{\mathrm{b}, \mathrm{c}}$ & 20.91 & $<0.01$ \\
Intracytoplasmic NTFA3 & $100 \pm 0.29$ & $186.67 \pm 15.28^{\mathrm{a}}$ & $313.33 \pm 32.15^{\mathrm{a}, \mathrm{c}}$ & 81.67 & $<0.01$ \\
NFAT3 in the nucleus & $100 \pm 0.1$ & $157.82 \pm 12.05^{\mathrm{a}}$ & $221.34 \pm 18.75^{\mathrm{a}, \mathrm{c}}$ & 66.63 & $<0.01$ \\
\hline
\end{tabular}

GRP78, 78 kDa glucose-regulated protein; ATF6, activating transcription factor; p, phosphorylated; TAK1, transforming growth factor-activated kinase 1; NTFA3, nuclear factor of activated T cells 3; Ena, enalapril; MI, myocardial infarction. ${ }^{a} \mathrm{P}<0.05$ and ${ }^{\mathrm{b}} \mathrm{P}<0.01$ vs. Sham group. ${ }^{\mathrm{c}} \mathrm{P}<0.05$ and ${ }^{\mathrm{d}} \mathrm{P}<0.01$ vs. MI group.

treatment with enalapril decreased myocardial fibrosis and increased cardiac systolic function in vivo. The specific myocardial fibrosis, EF and FS data are presented in Table I.

Enalapril decreases myocardial apoptosis in MI mice. To determine the role of enalapril in cardiac protection, enalapril was injected into the mouse abdominal cavity at 1 week after MI for 3 weeks. Myocardial apoptosis was detected via TUNEL staining in the infarct and border areas. As presented in Fig. 2A and B, there were no apoptosis-positive cells in the sham group. The number of TUNEL-positive cells increased significantly at 4 weeks after MI and a protective effect was observed in the enalapril-treatment group.

To additionally confirm the protective effect of enalapril, the expression levels of proteins involved in the caspase pathway were examined in the heart following MI by western blotting. The levels of cleaved PARP, cleaved caspase- 3 and cleaved caspase-9 decreased significantly following treatment with enalapril compared with the MI group (Fig. 2C and D). In addition, fewer cleaved caspase-3-positive cells were identified in the control group via immunohistochemical analysis. The number of cleaved caspase-3-positive cells increased significantly in the MI group, and the enalapril-treatment group exhibited protective effects (Fig. 2E). These results indicated that enalapril-treatment had a cardioprotective effect and significantly decreased activation of the caspase pathway. The complete data from the myocardial cell apoptosis staining and western blot analysis assays are presented in Table II.

Enalapril inhibits ER stress and mitochondrial dysfunction in MI mice. To confirm whether the cardioprotective effect of enalapril is associated with ER stress and mitochondrial dysfunction, the expression levels of ER stress- and mitochondrial dysfunction-associated proteins were measured. Western blot analysis indicated that the protein expression levels of GRP78 and ATF6 were significantly upregulated in the hearts of MI mice compared with the sham group. Furthermore, enalapril treatment inhibited the activation of ER stress-associated proteins in the hearts of MI mice (Fig. 3A). In addition, the western blot analysis results suggested that enalapril inhibited the upregulation of the mitochondrial dysfunction-associated proteins Bax and Bcl-2, which were induced by MI (Fig. 3B). To further understand the mechanism underlying the effect of enalapril on MI, activation of TAK1/NFAT downstream signaling was also analyzed by western blot analysis. As expected, enalapril treatment increased the phosphorylation of TAK1 and NFAT3 in the heart tissues of MI mice compared with the controls (Fig. 3C and D). Furthermore, immunohistochemistry confirmed the protein expression of NFAT3 (Fig. 3E), which was consistent with the western blot analysis data. In addition, compared with the MI group, enalapril treatment increased the nuclear transfer of NFAT3 (Fig. 4). In summary, 
A
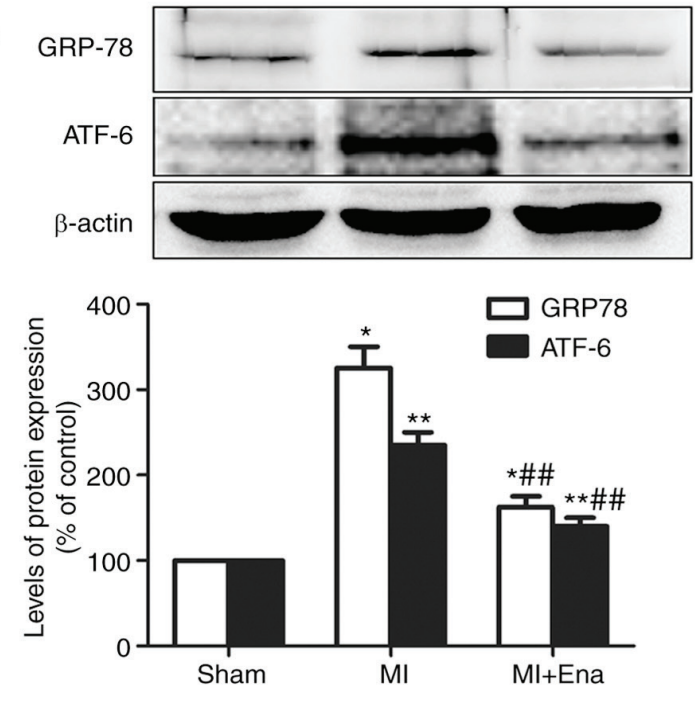

C
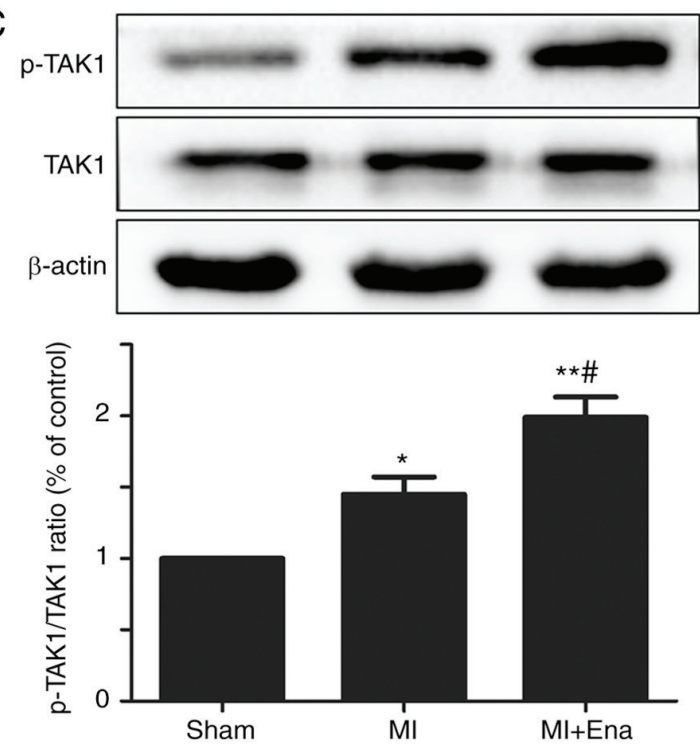

B
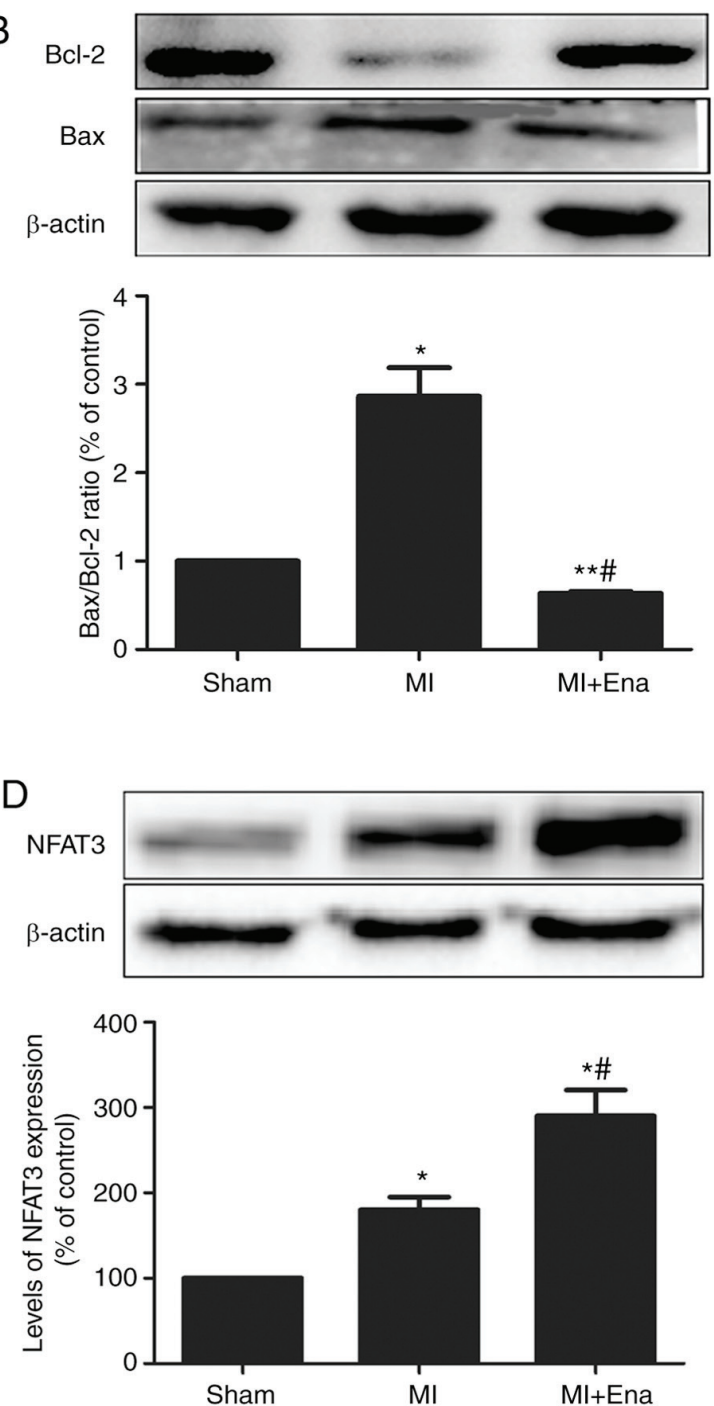

E

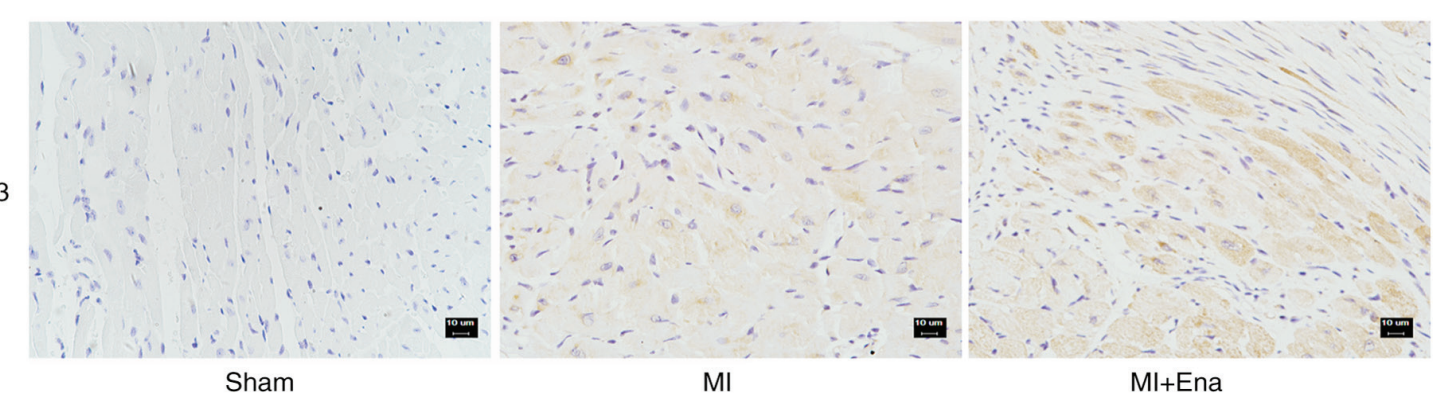

Figure 3. Enalapril inhibits ER stress and mitochondrial dysfunction in MI mice. (A) Protein expression levels and quantitative analysis of GRP78 and ATF6. (B) Protein expression levels and quantitative analysis of Bcl-2 and Bax. (C) Protein expression levels and quantitative analysis of TAK1 and p-TAK1. (D) Protein expression levels and quantitative analysis of intracytoplasmic NFAT3. (E) Immunohistochemical staining for NFAT3 in the hearts of control mice, MI mice and MI mice treated with enalapril. Magnification, $\mathrm{x} 400$. The data are presented as the mean \pm standard deviation $(\mathrm{n}=6) .{ }^{*} \mathrm{P}<0.05$ and ${ }^{* * *} \mathrm{P}<0.01$ vs. sham group. ${ }^{\prime \prime} \mathrm{P}<0.05$ vs. the MI group. Ena, enalapril; ER, endoplasmic reticulum; MI, myocardial infarction; GRP78, 78 kDa glucose-regulated protein; ATF6, activating transcription factor 6; TAK1, transforming growth factor- $\beta$-activated kinase 1; p, phosphorylated; NFAT3, nuclear factor of activated T cells 3.

these results suggested that the protective role of enalapril in MI was associated with the inhibition of ER stress, mitochondrial dysfunction and TAK1/NFAT signaling pathway. The complete western blot analysis data are summarized in Table III.

\section{Discussion}

The present study demonstrated that enalapril inhibited cardiomyocyte apoptosis, including via the inhibition of ER stress and mitochondrial dysfunction, and prevented 

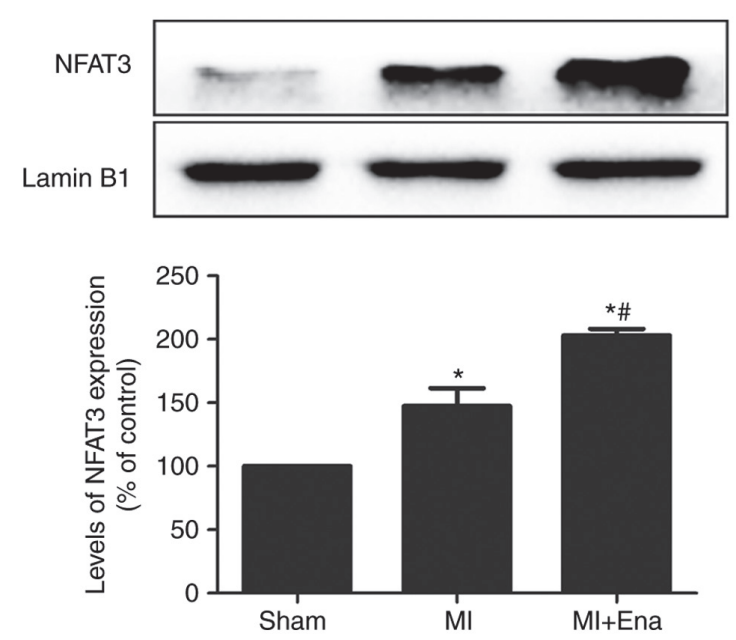

Figure 4. Nuclear protein expression levels and quantitative analysis of NFAT3 in MI mice. The data are presented as the mean \pm standard deviation $(\mathrm{n}=6) .{ }^{*} \mathrm{P}<0.05$ vs. sham group; ${ }^{\#} \mathrm{P}<0.05$ vs. MI group. Ena, enalapril; MI, myocardial infarction; NFAT3, nuclear factor of activated T cells 3 .

ventricular structural remodeling by activating the TAK1/NFAT pathway in vivo.

The morbidity and mortality rates of MI are high worldwide. Following infarction, myocardial injury is followed by apoptosis, inflammation and remodeling. The apoptosis of myocardial cells is an important inhibiting factor in myocardial recovery. Furthermore, it is a general consensus that MI activates the RAS, with high expression of Ang II, which is followed by ventricular remodeling. Concomitantly, calcium/calmodulin-dependent protein kinase II, which promotes cardiomyocyte apoptosis in vivo, is activated by Ang II following MI $(23,24)$. It has been demonstrated that Ang II is significantly increased in the infarct region of heart tissue (25). Enalapril, an angiotensin-converting enzyme inhibitor, inhibits the formation of Ang II and decreases the damage caused by Ang II. Several studies have also indicated that enalapril reduced the risk of MI (7), inhibited remodeling during the healing process after MI (26) and reduced mortality associated with cardiovascular events (6). Enalapril treatment also prevents apoptosis (9). The present study demonstrated that treatment with enalapril for 3 weeks prevented ventricular remodeling and apoptosis following MI.

TAK1, a member of the mitogen-activated protein kinase kinase kinase family, was originally identified as a candidate positive mediator of TGF- $\beta$ signal transduction (27). The TGF- $\beta 1-T A K 1-p 38$ mitogen activated protein kinase pathway is activated in post-MI left ventricular remodeling in rats, and the mRNA and protein levels of TAK1 are increased following MI (28). Furthermore, TAK1 is activated when cardiac progenitor cell apoptosis is inhibited in vitro and prevents heart failure progression following MI (29). Previous studies have proposed that TAK1 exerts a regulatory function in cell viability $(30,31)$. Fauster et al (32) also verified that TAK1 is a novel and direct target of ponatinib, an inhibitor of necroptosis. It was confirmed that TAK 1 activity is cardioprotective in muramyl dipeptide (MDP)-treated hearts in a mouse model of ischemia/reperfusion. Furthermore, the TAK1 inhibitor 5Z-7-oxozeanol abolished the decrease in infarct size observed in MDP-treated hearts (33). TAK1 regulates $\mathrm{NF}-\kappa \mathrm{B}$ signaling pathways that serve key roles in development, cell survival and immune responses (34). The evolutionarily conserved signaling intermediate in Toll pathways protein forms a signaling complex with TAK1 and TRAF6 through specific molecular interactions, where TAK1 may affect downstream cascade signaling for the activation of NF- $\kappa \mathrm{B}$ (35). Therefore, the expression of NF- $\kappa \mathrm{B}$ may be closely associated with the change in TAK1 expression. However, the specific association between NF- $\kappa \mathrm{B}$ and TAK1 in the treatment of MI with enalapril remains unknown.

The NFAT transcription factor family consists of 5 members: NFAT cytoplasmic (c)1, NFATc2, NFATc3, NFATc4 and NFAT5 (36). NFATc proteins are dephosphorylated and localize to the nucleus following treatment with calcineurin (36). A number of studies have reported that NF-ATc4 activation is increased following MI $(37,38)$. Furthermore, NFAT mediates cardioprotection in MI (39). Notably, TAK1 has been demonstrated to activate several signaling pathways, including calcineurin-NFAT signaling (40).

The present study also had certain limitations: Whether the treatment effect of enalapril was associated with the time intervals of enalapril treatment, or whether enalapril inhibited apoptosis via TAK1 through (5Z)-7-Oxozeaenol, which is a specific inhibitor of TAK1, are issues requiring additional study. To the best of our knowledge, the underlying mechanism of the effect of enalapril on MI remains incompletely understood. However, the results of the present study suggested novel possibilities for the mechanism of enalapril treatment.

\section{Acknowledgements}

Not applicable.

\section{Funding}

The present study was supported by the National Natural Science Fund Projects (grant nos. 81570238, 81570455 and 81770292), Technology Bureau of Wenzhou (grant no. Y20160027), Zhejiang Provincia Co-Constructed Project (grant no. WKJ-ZJ-1725) and the Project of Zhejiang Provincial Department of Health (grant no. 2017KY475).

\section{Availability of data and materials}

All data generated or analyzed during this study are included in this published article.

\section{Authors' contributions}

XR mainly completed statistical analysis of data and article modification; DHG performed the writing of this manuscript, TUNEL assay and animal model experiments; LLY performed the Western blot and Masson's trichrome (MT) staining; LL performed the echocardiographic measurements; MPC and HTL are corresponding authors and designed this study. 


\section{Ethics approval and consent to participate}

All animal experiments were approved by the Animal Ethics Committee of Wenzhou Medical University (approval no. wydw2017-0007) and were in accordance with the National Institute of Health Guidelines for the Care and Use of Laboratory Animals.

\section{Patient consent for publication}

Not applicable.

\section{Competing interests}

The authors declare that they have no competing interests.

\section{References}

1. Roth GA, Huffman MD, Moran AE, Feigin V, Mensah GA, Naghavi M and Murray CJ: Global and regional patterns in cardiovascular mortality from 1990 to 2013. Circulation 132: 1667-1678, 2015.

2. Whelan RS, Kaplinskiy V and Kitsis RN: Cell death in the pathogenesis of heart disease: Mechanisms and significance. Annu Rev Physiol 72: 19-44, 2010.

3. Zhang T, Zhang Y, Cui M, Jin L, Wang Y, Lv F, Liu Y, Zheng W, Shang H, Zhang J, et al: CaMKII is a RIP3 substrate mediating ischemia- and oxidative stress-induced myocardial necroptosis. Nat Med 22: 175-182, 2016.

4. Messadi-Laribi E, Griol-Charhbili V, Gaies E, Vincent MP, Heudes D, Meneton P, Alhenc-Gelas F and Richer C: Cardioprotection and kallikrein-kinin system in acute myocardial ischaemia in mice. Clin Exp Pharmacol Physio 35: 489-493, 2008.

5. Investigators S, Yusuf S, Pitt B, Davis CE, Hood WB and Cohn JN: Effect of enalapril on survival in patients with reduced left ventricular ejection fractions and congestive heart failure. $\mathrm{N}$ Engl J Med 325: 293-302, 1991.

6. Investigators S, Yusuf S, Pitt B, Davis CE, Hood WB Jr and Cohn JN: Effect of enalapril on mortality and the development of heart failure in asymptomatic patients with reduced left ventricular ejection fractions. N Engl J Med 327: 685-691, 1992.

7. Yusuf S, Pepine CJ, Garces C, Pouleur H, Salem D, Kostis J, Benedict C, Rousseau M, Bourassa M and Pitt B: Effect of enalapril on myocardial infarction and unstable angina in patients with low ejection fractions. Lancet 340: 1173-1178, 1992.

8. Szummer K, Wallentin L, Lindhagen L, Alfredsson J, Erlinge D, Held C, James S, Kellerth T, Lindahl B, Ravn-Fischer A, et al: Improved outcomes in patients with ST-elevation myocardial infarction during the last 20 years are related to implementation of evidence-based treatments: Experiences from the swedeheart registry 1995-2014. Eur Heart J 38: 3056-3065, 2017.

9. Velez Rueda JO, Palomeque J and Mattiazzi A: Early apoptosis in different models of cardiac hypertrophy induced by high renin-angiotensin system activity involves CaMKII. J Appl Physiol (1985) 112: 2110-2120, 2012.

10. Tang M, Wei X, Guo Y, Breslin P, Zhang S, Zhang S, Wei W, Xia Z, Diaz M, Akira S and Zhang J: TAK1 is required for the survival of hematopoietic cells and hepatocytes in mice. J Exp Med 205: 1611-1619, 2008.

11. Sakurai H: Targeting of TAK1 in inflammatory disorders and cancer. Trends Pharmacol Sci 33: 522-530, 2012.

12. Buglio D, Palakurthi S, Byth K, Vega F, Toader D, Saeh J, Neelapu SS and Younes A: Essential role of TAK1 in regulating mantle cell lymphoma survival. Blood 120: 347-355, 2012.

13. Schuman J, Chen Y, Podd A, Yu M, Liu HH, Wen R, Chen ZJ and Wang D: A critical role of TAK1 in B-cell receptor-mediated nuclear factor kappaB activation. Blood 113: 4566-4574, 2009.

14. Xiao Y, Li H, Zhang J, Volk A, Zhang S, Wei W, Zhang S, Breslin P and Zhang J: TNF- $\alpha /$ Fas-RIP-1-induced cell death signaling separates murine hematopoietic stem cells/progenitors into 2 distinct populations. Blood 118: 6057-6067, 2011.
15. De Windt LJ, Lim HW, Taigen T, Wencker D, Condorelli G, Dorn GW 2nd, Kitsis RN and Molkentin JD: Calcineurin-mediated hypertrophy protects cardiomyocytes from apoptosis in vitro and in vivo an apoptosis-independent model of dilated heart failure. Circ Res 86: 255-263, 2000.

16. Vashishta A, Habas A, Pruunsild P, Zheng JJ, Timmusk T and Hetman M: Nuclear factor of activated T-cells isoform c4 (NFATc4/NFAT3) as a mediator of antiapoptotic transcription in NMDA receptor-stimulated cortical neurons. J Neurosci 29: 15331-15340, 2009.

17. Stokes WS: Best practices for the use of animals in toxicological research and testing. Ann N Y Acad Sci 1245: 17-20, 2011.

18. Fink D, Romanowski K, Valuckaite V, Babrowski T, Kim M, Matthews JB, Liu D, Zaborina O and Alverdy JC: Pseudomonas aeruginosa potentiates the lethal effect of intestinal ischemia-reperfusion injury: The role of in vivo virulence activation. J Trauma 71: 1575-1582, 2011.

19. Liu YH, Xu J, Yang XP, Yang F, Shesely E and Carretero OA: Effect of ACE inhibitors and angiotensin II type 1 receptor antagonists on endothelial no synthase knockout mice with heart failure. Hypertension 39: 375-381, 2002.

20. Leuschner F, Panizzi P, Chico-Calero I, Lee WW, Ueno T, Cortez-Retamozo V, Waterman P, Gorbatov R, Marinelli B, Iwamoto $\mathrm{Y}$, et al: Angiotensin-converting enzyme inhibition prevents the release of monocytes from their splenic reservoir in mice with myocardial infarction. Circ Res 107: 1364-1373, 2010.

21. Tanaka M, Suemaru K, Watanabe S, Cui R, Li B and Araki H: Comparison of short- and long-acting benzodiazepine-receptor agonists with different receptor selectivity on motor coordination and muscle relaxation following thiopental-induced anesthesia in mice. J Pharmacol Sci 107: 277-284, 2008.

22. Li L, Chen Y, Doan J, Murray J, Molkentin JD and Liu Q: Transforming growth factor beta-activated kinase 1 signaling pathway critically regulates myocardial survival and remodeling. Circulation 130: 2162-2172, 2014.

23. Erickson JR, Joiner ML, Guan X, Kutschke W, Yang J, Oddis CV, Bartlett RK, Lowe JS, O'Donnell SE, Aykin-Burns N, et al: A dynamic pathway for calcium-independent activation of CaMKII by methionine oxidation. Cell 133: 462-474, 2008.

24. He BJ, Joiner ML, Singh MV, Luczak ED, Swaminathan PD, Koval OM, Kutschke W, Allamargot C, Yang J, Guan X, et al: Oxidation of CaMKII determines the cardiotoxic effects of aldosterone. Nat Med 17: 1610-1618, 2011.

25. Nakamura H, Umemoto S, Naik G, Moe G, Takata S, Liu P and Matsuzaki M: Induction of left ventricular remodeling and dysfunction in the recipient heart after donor heart myocardial infarction. J Am College Cardiol 42: 173-181, 2003.

26. Jugdutt BI, Menon V, Kumar D and Idikio H: Vascular remodeling during healing after myocardial infarction in the dog model: Effects of reperfusion, amlodipine and enalapril. J Am Coll Cardiol 39: 1538-1545, 2002.

27. Yamaguchi K, Shirakabe K, Shibuya H, Irie K, Oishi I, Ueno N, Taniguchi T, Nishida E and Matsumoto K: Identification of a member of the MAPKKK family as a potential mediator of TGF-beta signal transduction. Science 270: 2008-2011, 1995.

28. Matsumoto-Ida M, Takimoto Y, Aoyama T, Akao M, Takeda T and Kita T: Activation of TGF-beta1-TAK1-p38 MAPK pathway in spared cardiomyocytes is involved in left ventricular remodeling after myocardial infarction in rats. Am J Physiol Heart Circ Physiol 290: H709-H715, 2006.

29. Aonuma T, Takehara N, Maruyama K, Kabara M, Matsuki M, Yamauchi A, Kawabe J and Hasebe N: Apoptosis-resistant cardiac progenitor cells modified with apurinic/apyrimidinic endonuclease/redox factor 1 gene overexpression regulate cardiac repair after myocardial infarction. Stem Cells Transl Med 5: 1067-1078, 2016.

30. Morioka S, Inagaki M, Komatsu Y, Mishina Y, Matsumoto K and Ninomiya-Tsuji J: TAK1 kinase signaling regulates embryonic angiogenesis by modulating endothelial cell survival and migration. Blood 120: 3846-3857, 2012.

31. Mihaly SR, Ninomiya-Tsuji J and Morioka S: TAK1 control of cell death. Cell Death Differ 21: 1667-1676, 2014.

32. Fauster A, Rebsamen M, Huber KV, Bigenzahn JW, Stukalov A, Lardeau CH, Scorzoni S, Bruckner M, Gridling M, Parapatics K, et al: A cellular screen identifies ponatinib and pazopanib as inhibitors of necroptosis. Cell Death Dis 6: e1767, 2015.

33. Sicard P, Jacquet S, Kobayashi KS, Flavell RA and Marber MS: Pharmacological postconditioning effect of muramyl dipeptide is mediated through RIP2 and TAK1. Cardiovasc Res 83: 277-284, 2009. 
34. Endale M, Kim TH, Kwak YS, Kim NM, Kim SH, Cho JY, Yun BS and Rhee MH: Torilin inhibits inflammation by limiting TAK1-mediated map kinase and NF- $\kappa \mathrm{B}$ activation. Mediators Inflamm 2017: 7250968, 2017.

35. Wi SM, Moon G, Kim J, Kim ST, Shim JH, Chun E and Lee KY: TAK1-ECSIT-TRAF6 complex plays a key role in the TLR4 signal to activate NF-кB. J Biol Chem 289: 35205-35214, 2014.

36. Crabtree GR and Olson EN: NFAT signaling: Choreographing the social lives of cells. Cell 109: S67-S79, 2002.

37. Crabtree GR: Generic signals and specific outcomes: Signaling through Ca2+, calcineurin, and NF-AT. Cell 96: 611-614, 1999.

38. Echtermeyer F, Harendza T, Hubrich S, Lorenz A, Herzog C, Mueller M, Schmitz M, Grund A, Larmann J, Stypmann J, et al: Syndecan-4 signalling inhibits apoptosis and controls NFAT activity during myocardial damage and remodelling. Cardiovasc Res 92: 123-131, 2011.
39. Bueno OF, Lips DJ, Kaiser RA, Wilkins BJ, Dai YS, Glascock BJ, Klevitsky R, Hewett TE, Kimball TR, Aronow BJ, et al: Calcineurin abeta gene targeting predisposes the myocardium to acute ischemia-induced apoptosis and dysfunction. Circ Res 94: 91-99, 2004.

40. Li L, Chen Y, Li J, Yin H, Guo X, Doan J, Molkentin JD and Liu Q: TAK1 regulates myocardial response to pathological stress via NFAT, NFkB, and Bnip3 pathways. Sci Rep 5: 16626 , 2015.

(i) $\Theta$ This work is licensed under a Creative Common Attribution-NonCommercial-NoDerivatives 4.0 International (CC BY-NC-ND 4.0) License. 